\title{
Palladium-catalyzed Decarbonylative Catellani Reaction
}

Ming-Liang Han, ${ }^{1, \dagger}$ Jun-Jie Chen, ${ }^{1, \dagger}$ Hui Xu, ${ }^{1}$ Zhi-Cong Huang, ${ }^{1,2}$ Wei Huang, ${ }^{1}$ Yu-Wen Liu, ${ }^{1,2}$ Xing Wang, ${ }^{1,2}$ Min Liu,${ }^{1,2}$ Zi-Qiong Guo, ${ }^{1}$ Hui-Xiong Dai*1,2

The transition metal-catalyzed Catellani reaction of aryl halides has drawn significant attentions as an efficient and practical tool for the synthesis of substituted arenes. We describe herein the palladium-catalyzed, norbornene (NBE)-mediated synthesis of polysubstituted arenes from aromatic acids via decarbonylative Catellani reaction. A variety of alkenyl, alkyl, aryl and sulfur moieties could be conveniently introduced into the ipso-positions of aromatic thioesters. By merging carboxyl-directed $\mathbf{C}-\mathrm{H}$ functionalization and the classical Catellani reactions, our protocol allowed the construction of 1,2,3-trisubstituted and 1,2,3,4-tetrasubstituted arenes from simple aromatic acids. Furthermore, the late-stage functionalization of a series of drug molecules highlights the potential utility of the reaction.

The Pd/norbornene (NBE) cooperative catalysis offers distinct access to multisubstituted arenes. ${ }^{1}$ The high ring strain of the [2.2.1] bicyclic scaffold together with its structural rigidity enables the NBE to function as a transient mediator to complete intermolecular carbopalladation and final extrusion. ${ }^{2}$ In 1997, Catellani and coworkers disclosed the first cooperative $\mathrm{Pd} / \mathrm{NBE}$-catalyzed reaction using aryl iodides, allowing for the expeditious synthesis of ipso-ortho bifunctionalized arenes (Figure 1a). ${ }^{3}$ Following this initial breakthrough, Lautens, Dong and others have greatly enriched this chemistry in the past few years, making this methodology a reliable route for the synthesis of complex arenes. ${ }^{4}$ It is noteworthy that the Dong group recently synthesized tetrasubstituted alkenes via a palladium/NBE catalyzed alkenyl Catellani reaction. ${ }^{5}$ With NBE as a transient mediator, Bach first developed a Pd(II)-initiated 2-functionalization of indoles and pyrroles. ${ }^{6}$ In 2015 , Yu creatively combined the amide directed ortho $\mathrm{C}-\mathrm{H}$ activation and $\mathrm{Pd} / \mathrm{NBE}$ chemistry, which subtly achieved meta-selective inert $\mathrm{C}-\mathrm{H}$ alkylation and arylation. ${ }^{7}$ Subsequently, this norbornene relay approach ${ }^{1}$ Chinese Academy of Sciences Key Laboratory of Receptor Research, Shanghai Institute of Materia Medica, University of Chinese Academy of Sciences, Shanghai 201203, China. ${ }^{2}$ University of Chinese Academy of Sciences, Beijing 100049, China. ${ }^{\dagger}$ These authors contributed equally: Ming-Liang Han and Jun-Jie Chen. *e-mail: hxdai@ simm.ac.cn 
has been extensively applied in meta- and para-C-H activations. ${ }^{8}$ Recently, the Dong group reported a distal alkenyl C-H functionalization through this directed Pd/NBE cooperative catalysis. ${ }^{9}$ Furthermore, $\mathrm{Pd}(\mathrm{II})$-initiated Catellani-type reactions with arylboron species have been elegantly realized by Zhou, Zhang and Dong. ${ }^{10}$

The carboxylic acid functionality is ubiquitous in natural products, drugs, and agrochemicals. Their benign syntheses and structural diversities enable the carboxylic acids to play an important role in organic chemistry. ${ }^{11}$ Over the past few years, transition metal-catalyzed transformations of aryl carboxylic acids into new $\mathrm{C}-\mathrm{C}$ and $\mathrm{C}$-heteroatom bonds have drawn significant attention as an alternative to traditional cross-coupling procedures. In 2002, Myers disclosed a Pdcatalyzed decarboxylative Heck-type olefination of aromatic acids. ${ }^{12}$ Subsequently, Gooßen reported a $\mathrm{Pd} / \mathrm{Cu}-$ cocatalyzed decarboxylative coupling between aromatic acids and aryl halides to form biaryl skeletons. ${ }^{13}$ Since these seminal works, tremendous progress has been made in the area of decarboxylative cross-coupling reactions of aromatic acids. ${ }^{14}$ Moreover, carboxyl groups are efficient directing groups in $\mathrm{C}-\mathrm{H}$ functionalization. ${ }^{15}$ Carboxyl-directed ortho$\mathrm{C}-\mathrm{H}$ functionalization and subsequent ipso-decarboxylation is a promising approach for the construction of polysubstituted arenes, ${ }^{16}$ which are ubiquitous structural cores in medicinal and material science. ${ }^{17}$ However, these reactions mainly focus on decarboxylative protonation. Thus, the development and validation of a general approach to achieve decarboxylative bis- and even poly-functionalization of broadly available aromatic acids is still a challenge. ${ }^{18}$

Thioesters are common intermediates in both organic synthesis and biochemical processes. ${ }^{19}$ Compared with other carboxylic acid derivatives, thioesters are stable but reactive, and can facilitate the oxidative addition of $\mathrm{C}(\mathrm{O})-\mathrm{S}$ to lowvalent transition-metal species. ${ }^{20}$ Further decarbonylation of the thioester affords the ArM species, which then undergoes the cross coupling reaction with the nucleophiles. ${ }^{21}$ In connection with our interest in thioester and Catellani reaction, we envisage that a combination of $\mathrm{Pd}(0) / \mathrm{NBE}$ and aromatic thioesters could afford the 1,2-disubstituted arenes via decarbonylation of the thioester and subsequent NBE-mediated ortho- $\mathrm{C}-\mathrm{H}$ and ipso-C-Pd functionalizations. Herein, we report a cooperative palladium-catalyzed, NBE-mediated disubstitution of (hetero)aromatic thioesters via decarbonylative Catellani reaction (Figure 1b). The potential applications of this protocol were demonstrated by the late-stage bifunctionalization of some commercial drugs and construction of polysubstituted arenes from aromatic acids. 


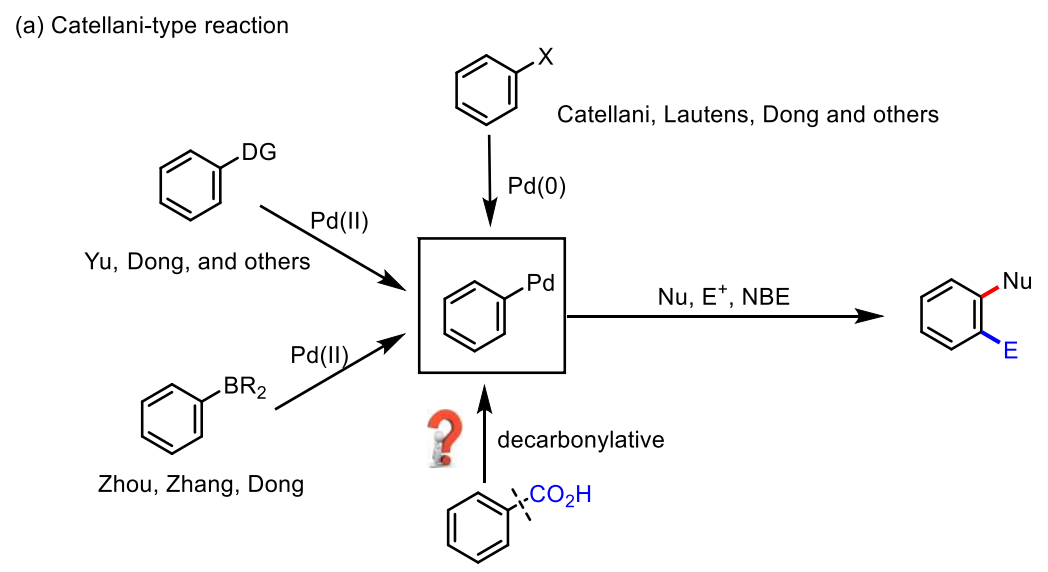

(b) This work: Decarbonylative Catellani Reaction of Thioester

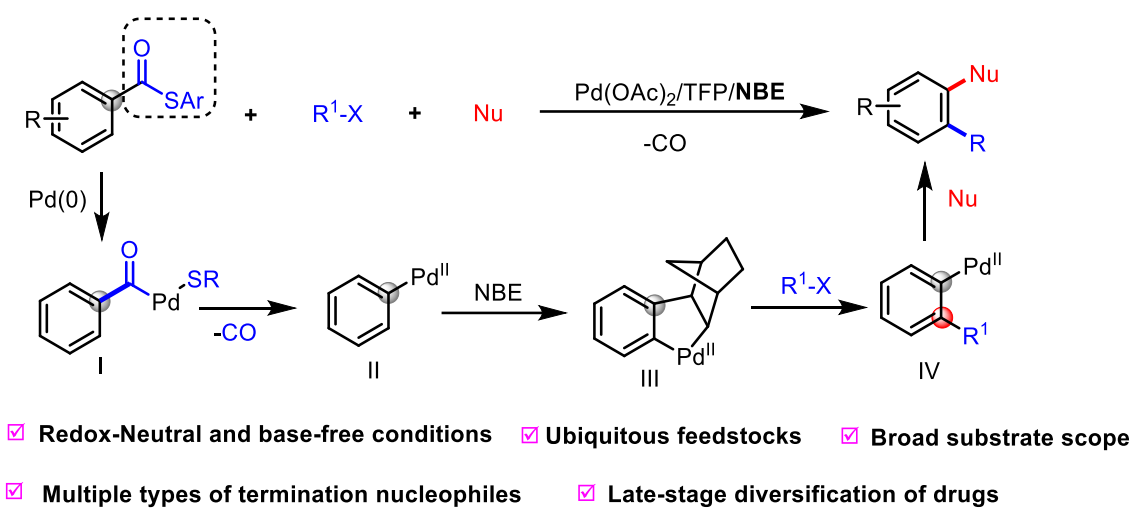

Fig. 1 | Catellani-type Reaction.

\section{Results and discussion}

We began our investigation by choosing $S$-( $p$-tolyl) naphthalene-1-carbothioate 1a as the model substrates, ethyl acrylate $\mathbf{2 a}$ as the nucleophile, and benzyl bromide $\mathbf{3} \mathbf{a}$ as the electrophile. After screening of various reaction parameters, the desired product $4 \mathbf{a}$ was obtained in $68 \%$ yield in the presence of $\mathrm{Pd}(\mathrm{OAc})_{2}(10 \mathrm{~mol} \%)$, TFP $(25 \mathrm{~mol} \%)$, norbornene (NBE) (1.5 equiv.), and $\mathrm{Cu}_{2} \mathrm{O}$ (1.5 equiv.) at $120^{\circ} \mathrm{C}$ (Table 1, entry 1$)$. Control experiments indicated that the palladium, phosphine ligand (TFP), NBE and $\mathrm{Cu}_{2} \mathrm{O}$ were all essential for the reaction (Table 1, entries 2-5). Other palladium catalysts could also afford the desired product, albeit in lower yields (Table 1, entry 6). In Catellani-type reactions, the addition of an exogenous base is often required. ${ }^{1 f}$ To our delight, our protocol was able to proceed under

\section{Table 1. | Reaction Optimization}




Reaction condition variations
(3a $(3.0$ eq. $)$

${ }^{a}$ Reactions were run on a $0.10 \mathrm{mmol}$ scale. Yields were determined from the crude ${ }^{1} \mathrm{H}$ NMR spectra using $\mathrm{CH}_{2} \mathrm{Br}_{2}$ as an internal standard. TFP = tri(2-furyl)phosphine.

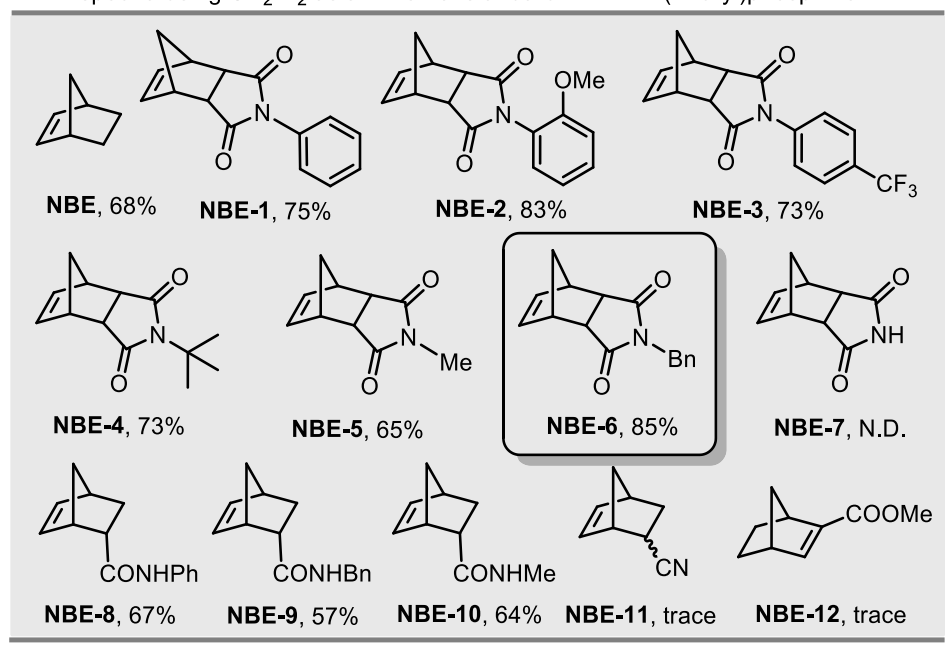

base-free condition and diminished yields were observed in the presence of bases (Table 1, entries 7, 8). Among the various phosphine ligands (Table S3), TFP delivered the best yields (Table 1, entries 9, 10). Copper salts are often required as activators to accelerate the $\mathrm{C}(\mathrm{O})-\mathrm{S}$ cleavage. ${ }^{22}$ After screening of various copper salts, we found $\mathrm{Cu}_{2} \mathrm{O}$ was the best (Table 1, entries 11, 12). To further enhance the reactivity, a series of modified NBEs were prepared and examined. Compared to simple NBE, succinimide-containing NBEs with relatively bulkier substituents at the $N$-position were found to be more efficient (NBE-1-4). In contrast, the $N$-methyl substituted NBE (NBE-5) was inferior, and unprotected succinimide-derived NBE (NBE-7) was completely ineffective. To our delight, $N$-benzyl substituted NBE (NBE-6) delivered the best yield (85\%). C5 amide-substituted NBEs (NBE-8-10) were less effective. Both 5-cyano substituted NBE (NBE-11) and 2-methyl ester substituted NBE (NBE-12) afforded trace amounts of desired products. 
With the above optimal reaction conditions in hand, we first examined the thioester scope (Table 2). Polycyclic substrates containing a naphthyl or pyrenyl moiety afforded moderate to good yields $(\mathbf{4 a}-\mathbf{4 c}, \mathbf{4 w})$. Ortho-substituted thioesters $(\mathbf{1 d}-\mathbf{1 s})$ bearing both electron-donating and electron-withdrawing substituents were all compatible with the reaction conditions, and a variety of tri- and tetrasubstituted arenes were obtained in yields of $30-87 \%$ (4d-4s). Aryl bromides, which are commonly employed as aryl electrophiles in transition metal-catalyzed cross-couplings, were

Table 2. | Scope of aryl thioesters, olefins and benzyl bromides

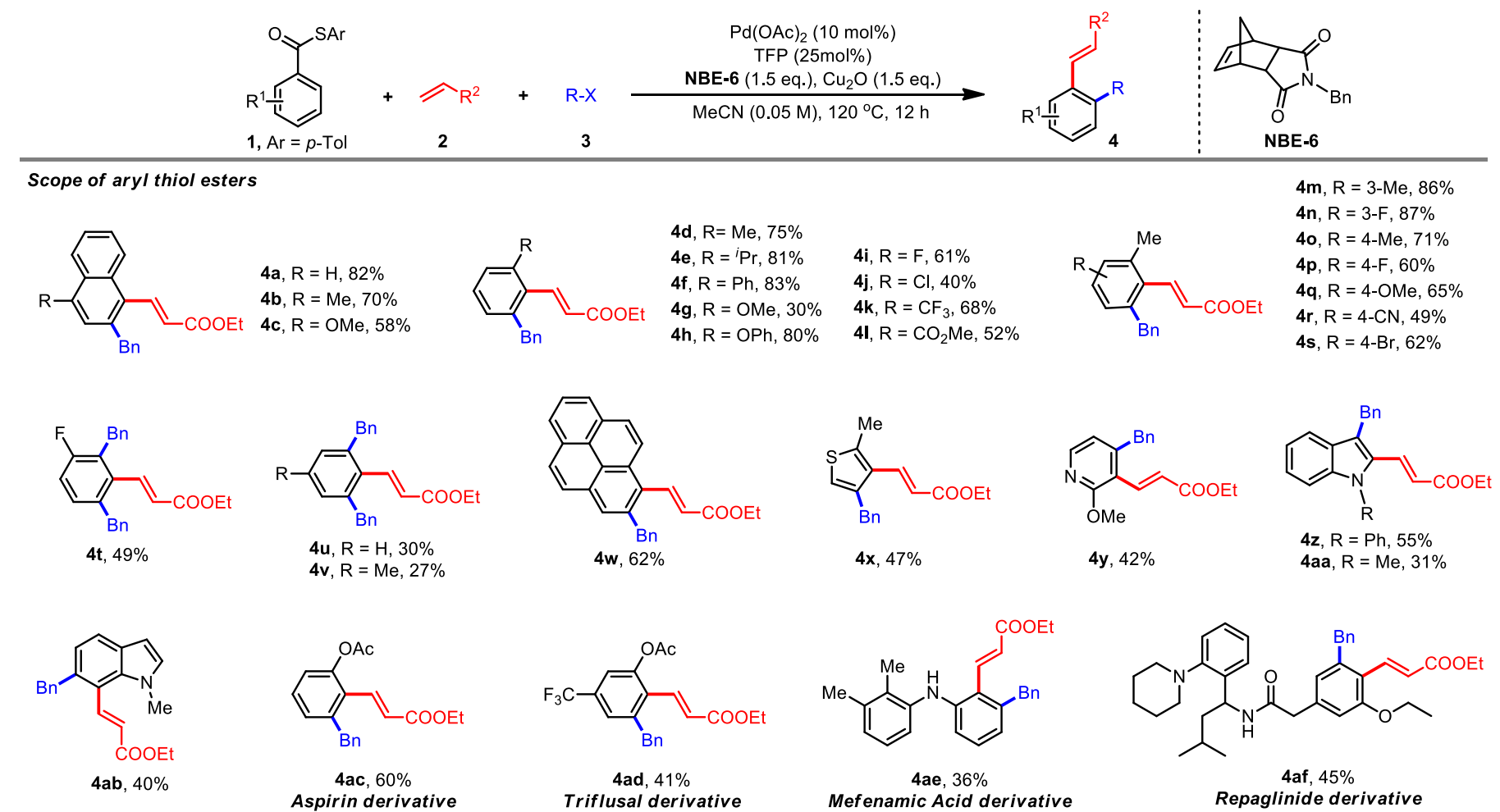

Scope of olefin

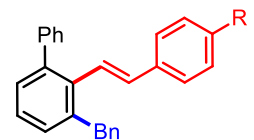
4ag, $R=M e, 89 \%$ 4ah, $R=F, 90 \%$ 4ai, $\mathrm{R}=\mathrm{CF}_{3}, 78 \%$ 4aj, $R=O M e, 83 \%$ 4ak, $R=H, 91 \%$<smiles>Brc1ccccc1-c1ccccn1</smiles>
4al, $72 \%$<smiles>CCOC=Cc1ccccc1Cc1ccc(Cl)cc1</smiles>

4ar, $67 \%$<smiles>N#C/C=C/c1ccccc1</smiles>
4am, 93\%<smiles>C=C(Oc1ccccc1OC1CCCCC1)c1ccccc1</smiles>

4an, $53 \%$<smiles>CC(=O)C1=CC2=CC=CC2=[NH+]1</smiles>
4ao, $73 \%$

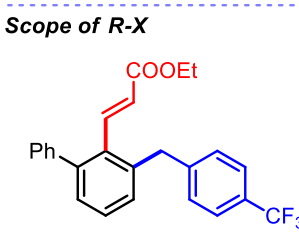

4ap, $62 \%$<smiles>CCOC(=O)c1c(Cc2ccc(F)cc2)cccc1-c1ccccc1</smiles>

4aq, $52 \%$<smiles>CCOC=Cc1ccccc1Cc1ccc(Br)cc1</smiles>

4as, $67 \%$<smiles>CCOC(=O)c1c(-c2ccccc2)cccc1-c1ccc(C)cc1</smiles>

4at, $80 \%$

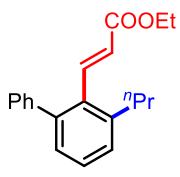

4au, $40 \%^{a}$

Reaction conditions: $1(0.1 \mathrm{mmol}), 2(0.15 \mathrm{mmol}), 3(0.3 \mathrm{mmol}), \mathrm{Pd}(\mathrm{OAc})_{2}(0.01 \mathrm{mmol}), \operatorname{TFP}(0.025 \mathrm{mmol}), \mathbf{N B E}-6(0.15 \mathrm{mmol}), \mathrm{Cu} 2 \mathrm{O}(0.15 \mathrm{mmol}), \mathrm{MeCN}(2 \mathrm{~mL}), 120^{\circ} \mathrm{C}, 12 \mathrm{~h}$ Isolated yields are reported. ${ }^{\mathrm{a}_{1}}$-lodopropane was used in the reaction.

well tolerated, providing a handle for further functionalization. For ortho-unsubstituted aryl thioesters, dibenzylated products were obtained $(\mathbf{4 t}-\mathbf{4 v})$. Substrates bearing thiophene, pyridine and indole groups provided the desired products 
in moderate yields $(\mathbf{4} \mathbf{x}-\mathbf{4 a b})$. The synthetic utility of our protocol was further showcased by the diversification of commercial pharmaceuticals, including aspirin, triflusal, mefenamic acid and repaglinide, furnishing the corresponding products (4ac-4af) in acceptable yields. The scope with respect to the olefin terminating reagents was next investigated. In addition to ethyl acrylate, other electron-deficient olefins, such as acrylonitrile (4am), 2-vinylpyridine (4al), and especially methyl methacrylate (4ao) could be smoothly introduced at the ipso-position. Gratifyingly, styrene and its derivatives, irrespective of bearing electron-donating or electron-withdrawing groups, could serve as effective terminating reagents (4ak-4aj). Intriguingly, when the electron rich and less reactive cyclohexyl vinyl ether was subjected to the reaction conditions, compound 4an bearing branched alkenyl ethers was isolated in 53\% yield. Regarding the scope of the electrophiles, benzyl bromides containing trifluoromethyl (4ap), fluorine (4aq), chlorine (4ar), bromine (4as) and methyl (4at) functionalities were all suitable substrates. Ortho-alkylated product 4au was obtained in $40 \%$ yield when 1-iodopropane was employed.

To further illustrate the feasibility of this protocol, an ortho-benzylation/ipso-Suzuki cascade of aryl thioesters was carried out (Table 3). By employing thioester 1a, benzyl bromide 3a and arylboronic acid as the substrates, ipso-arylation occurred smoothly with moderate to good yields $(\mathbf{5 a}-\mathbf{5 q})$. Aryl boronic acids containing ester $(\mathbf{5 b})$, chloro (5c), bromo (5e), trimethylsilyl (5h) and nitro (5k) groups were well tolerated, offering additional opportunity for further structural elaboration. When ortho-substituted aryl thioesters were subjected to the reaction conditions, multi-substituted biaryl skeletons were obtained (5r, 5s). Ipso-methylation product $(\mathbf{5 t})$ was synthesized in 36\% yield using methylboronic acid as the terminating reagent. Subsequently, we employed allylic alcohol as the terminating nucleophile. A variety of ketone and aldehyde products were obtained via chain-walking strategies $(\mathbf{5 u}-\mathbf{5 a a}) \cdot{ }^{23}$ It is worth noting that citronellal- and Lily aldehyde-derived allylic alcohols afforded the corresponding products $\mathbf{5 y}$ and $\mathbf{5 z}$ in $61 \%$ and $51 \%$ yields, respectively. Thioesters are versatile synthons for the synthesis of thioethers. ${ }^{24}$ In the absence of terminating nucleophiles, ortho- $\mathrm{C}-\mathrm{H}$ benzylation and ipso-decarbonylative thiolation of aryl thioester 1a furnished the thioether product 5ab in 67\% yield after further optimization of the reaction conditions (see Supplementary Information). Aryl and alkyl thiols could be readily introduced to the ipso-positions, leading to polysubstituted thioethers in acceptable 
yields (5ab-5ae).

Table 3. | Scope of boronic acids, alkenyl alcohols and thiols
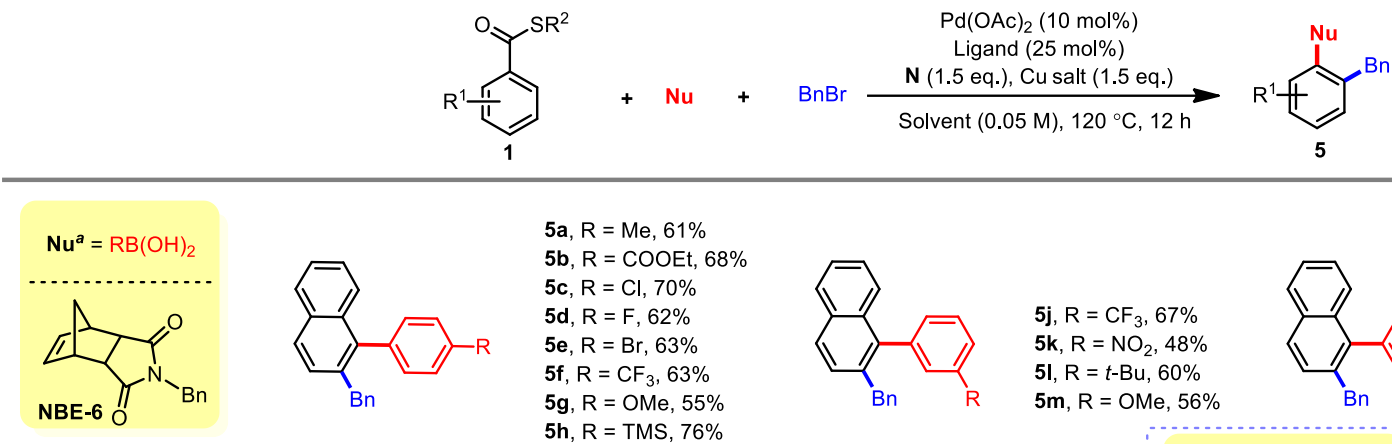
$\mathbf{5 a}, \mathrm{R}=\mathrm{Me}, 61 \%$
$\mathbf{5 b}, \mathrm{R}=\mathrm{COOEt}, 68 \%$ 5c, $\mathrm{R}=\mathrm{Cl}, 70 \%$ 5d, $R=F, 62 \%$ 5e, $\mathrm{R}=\mathrm{Br}, 63 \%$ 5f, $\mathrm{R}=\mathrm{CF}_{3}, 63 \%$ 5g, $\mathrm{R}=\mathrm{OMe}, 55 \%$ 5h, R = TMS, $76 \%$ $5 i, \mathrm{R}=\mathrm{H}, 55 \%$
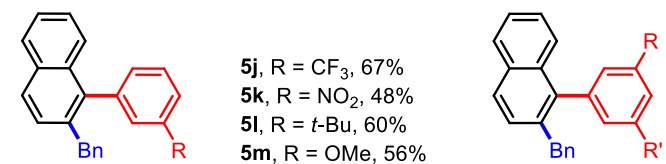

n, $R^{1}=R^{2}=M e, 51 \%$ 5o, $\mathrm{R}^{1}=\mathrm{R}^{2}=\mathrm{CF}_{3}, 55 \%$ $5 \mathrm{I}, \mathrm{R}=t-\mathrm{Bu}, 60 \%$

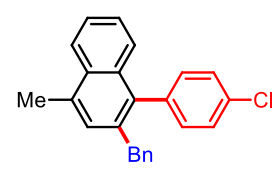

$5 q, 60 \%$

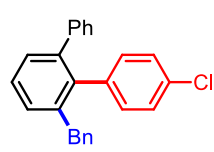

5r, $40 \%$

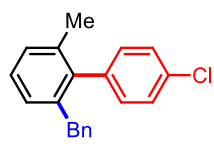

5s, $56 \%$

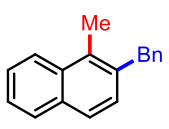

5t, $36 \%$

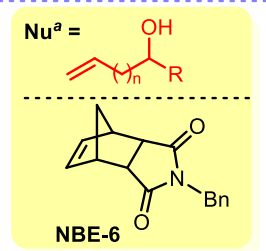

NBE-6

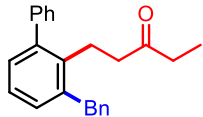

$5 u, 63 \%$

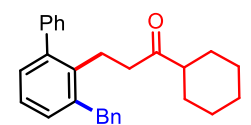<smiles>O=C(CCc1ccccc1)c1ccc(I)cc1</smiles>
$\mathrm{R}=\mathrm{CF}_{3}, 5 \mathrm{w}, 50 \%$

5v, $65 \%$ $\mathrm{R}=\mathrm{H}, \mathbf{5 x}, 52 \%$<smiles>CC(C)=CCCC(C)CCC(=O)CCc1c(O)cccc1Br</smiles>
Citronellal derivative

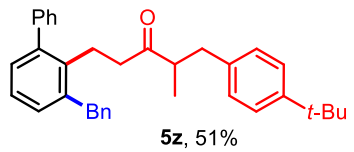
Lily aldehyde derivative

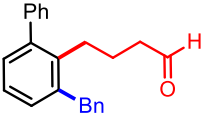

5aa, $38 \%^{\mathrm{b}}$

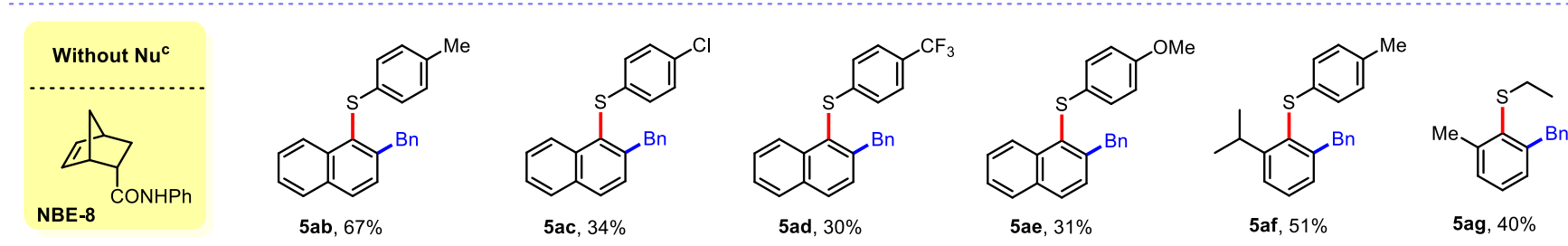

${ }^{a} \mathrm{R}=p$-Toluene. Reaction conditions:1 $(0.1 \mathrm{mmol}), \mathrm{Nu}(0.15 \mathrm{mmol})$, benzyl bromide $(0.3 \mathrm{mmol}), \mathrm{Pd}(\mathrm{OAc})_{2}(0.01 \mathrm{mmol}), \mathrm{TFP}(0.025 \mathrm{mmol}), \mathrm{NBE}-6(0.15 \mathrm{mmol}), \mathrm{Cu} \mathrm{O}(0.15 \mathrm{mmol})$, $\operatorname{MeCN}(2 \mathrm{~mL}), 120^{\circ} \mathrm{C}, 12 \mathrm{~h}$. ${ }^{b}$ but-3-en-1-ol was used as Nu. ${ }^{c}$ Decarboxylative thiolation reactions: $1(0.1 \mathrm{mmol})$, benzyl bromide $(0.3 \mathrm{mmol}), \mathrm{Pd}(\mathrm{OAc})_{2}(0.01 \mathrm{mmol}),(p-\mathrm{MePh})_{3} \mathrm{P}$ $(0.025 \mathrm{mmol}), \mathrm{NBE}-8(0.15 \mathrm{mmol}), \mathrm{CuCl}(0.15 \mathrm{mmol}), \mathrm{K}_{2} \mathrm{CO}_{3}(0.2 \mathrm{mmol}), \mathrm{THF}(2 \mathrm{~mL}), 120^{\circ} \mathrm{C}, 12 \mathrm{~h}$. Isolated yields are reported.

The synthetic utility of this methodology was further demonstrated in the late-stage diversification of thioesters 1al derived from 3-methylflavone-8-carboxylic acid, a drug used for the treatment of coronary heart disease (Figure 2a). Ortho-benzylation and a subsequent ipso-Heck- or Suzuki cascade of aryl thioester 1al gave the product $\mathbf{6 a}$ and $\mathbf{6 b}$ in $44 \%$ and $50 \%$ yields, respectively. When pent-1-en-3-ol was used as a terminating nucleophile, an ipso-alkylated product $\mathbf{6 c}$ was synthesized in $49 \%$ yield. In addition, thiolation terminated derivative $\mathbf{6 d}$ was isolated in $31 \%$ yield. The carboxylate functionality is a practical directing group in transition metal-catalyzed $\mathrm{C}-\mathrm{H}$ bond functionalization. ${ }^{5}$ Thus, 1,2,3-trisubstituted arene $\mathbf{4 g}$ and 1,2,3,4-tetrasubstituted arene $\mathbf{7 d}$ were readily synthesized from benzoic acid by a combination of ortho $\mathrm{C}-\mathrm{H}$ functionalization, the Catellani reaction, and $\mathrm{Pd} / \mathrm{NBE}$ catalyzed ipso-alkenylation/ortho- 


\section{Fig. 2 | Synthetic applications}
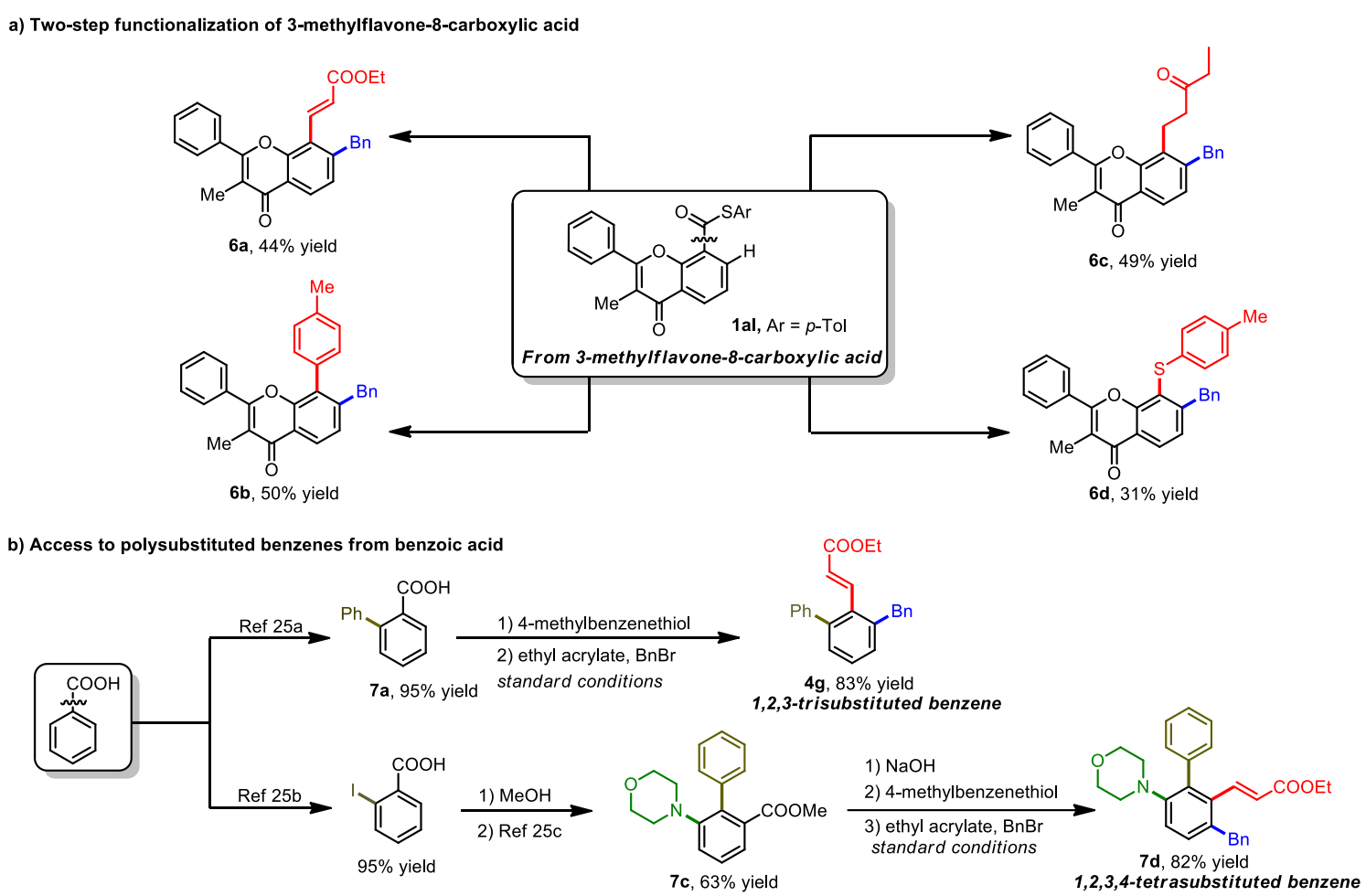

\section{Conclusion}

In summary, we have developed a new protocol for the palladium-catalyzed, norbornene (NBE)-mediated decarbonylative Catellani reaction of aromatic thioesters. Our protocol utilizes widely available aryl carboxylic acids as feedstocks and featured redox-neutral and base-free reaction conditions. The termination step is flexible, which is demonstrated by Heck reaction, Suzuki coupling, alkylation and thiolation. Synthetic utility of this protocol is further highlighted by late-stage diversification of some pharmaceutical drugs. Carboxyl-directed ortho $\mathrm{C}-\mathrm{H}$ iodination, Catellani reaction, and subsequent decarbonylative Catellani reaction allowed for the rapid construction of trisubstituted and tetrasubstituted arene from benzoic acid.

\section{Data availability}

The data supporting the findings of this study are available within the article and its Supplementary Information Files.

Acknowledgements We gratefully acknowledge the Shanghai Institute of Materia Medica, the Chinese Academy of Sciences, the NSFC (21772211), the Youth Innovation Promotion Association CAS (No. 2014229 and 2018293), the Science and Technology Commission of Shanghai Municipality (17JC1405000 and 18431907100), the Program of Shanghai Academic Research Leader (19XD1424600), the National Science \& Technology Major Project "Key New 
Drug Creation and Manufacturing Program", China (2018ZX09711002-006) for financial support.

Competing interests The authors declare no competing interests.

\section{REFERENCES}

(1) a) M. Catellani, Top. Organomet. Chem. 2005, 14, 21; b) A. Martins, B. Mariampillai, M. Lautens, Top. Curr. Chem. 2009, 292, 1; c) J. Ye, M. Lautens, Nat. Chem. 2015, 7, 863; d) N. Della, Ca', M. Fontana, E. Motti, M. Catellani, Acc. Chem. Res. 2016, 49, 1389; e) H.-G. Cheng, S.-Q. Chen, R.-M. Chen, Q.-H. Zhou, Angew. Chem., Int. Ed. 2019, 58, 5832; f) J.-C. Wang, G.-B. Dong, Chem. Rev. 2019, 119, 7478.

(2) a) P. R. Khoury, J. D. Goddard, W. Tam, Tetrahedron 2004, 60, 8103; b) R.-H. Li, G.-B. Dong, J. Am. Chem. Soc. 2020, $142,17859$.

(3) M. Catellani, F. Frignani, A. Rangoni, Angew. Chem., Int. Ed. Engl. 1997, 36, 119.

(4) a) M. Lautens, S. Piguel, Angew. Chem., Int. Ed. 2000, 39, 1045; b) Z. Dong, G.-B. Dong, J. Am. Chem. Soc. 2013, 135, 18350; c) J.-C. Wang, R.-H. Li, Z. Dong, P. Liu, G.-B. Dong, Nat. Chem. 2018, 10, 866; d) Q.-W. Gao, Y. Shang, F.-Z. Song, J.-X. Ye, Z.-S. Liu, L.-S. Li, H.-G. Cheng, Q.-H. Zhou, J. Am. Chem. Soc. 2019, 141, 15986; e) W.-W. Lv, Y.-H. Chen, S. Wen, D. Ba, G.-L. Cheng, J. Am. Chem. Soc. 2020, 142, 14864; f) Z.-S. Liu, Y. Hua, Q.W. Gao, Y.-Y. Ma, H. Tang, Y. Shang, H.-G. Cheng, Q.-H. Zhou, Nat. Catal. 2020, 3, 727; g) J. Wang, C. Qin, J.P. Lumb, X.-J. Luan, Chem 2020, 6, 1; h) F.-G. Sun, M. Li, C.-F. He, B. Wang, B. Li, X.-W. Sui, Z.-H. Gu, J. Am. Chem. Soc. 2016, 138, 7456.

(5) J.-C. Wang, Z. Dong, C. Yang, G.-B. Dong, Nat. Chem. 2019, 11, 1106.

(6) a) M. Wegmann, M. Henkel, T. Bach, Org. Biomol. Chem. 2018, 16, 5376; b) L. Jiao, T. Bach, J. Am. Chem. Soc. 2011, 133, 12990; c) L. Jiao, E. Herdtweck, T. Bach, J. Am. Chem. Soc. 2012, 134, 14563.

(7) X.-C. Wang, W. Gong, L.-Z. Fang, R.-Y. Zhu, S. H. Li, K. M. Engle, J.-Q. Yu, Nature 2015, 519, 334.

(8) a) Z. Dong, J. Wang, G. Dong, J. Am. Chem. Soc. 2015, 137, 5887; b) H. Shi, A. N. Herron, Y. Shao, Q. Shao, J.Q. Yu, Nature 2018, 558, 581; c) W.-W. Lv, Y.-H. Chen, S. Wen, D. Ba, G.-L. Cheng, J. Am. Chem. Soc. 2020, 142, 
14864; d) H. Shi, Y. Lu, J. Weng, K. L. Bay, X.-Y. Chen, K. Tanaka, P. Verma, K. N. Houk, J.-Q. Yu, Nat. Chem. 2020, 12, 399; e) U. Dutta, S. Porey, S. Pimparkar, A. Mandal, J. Grover, A. Koodan, D. Maiti, Angew. Chem. Int. Ed. 2020, 59, 20831.

(9) Wu, Z.; Fatuzzo, N.; Dong, G.-B. Distal alkenyl C-H functionalization via the palladium/norbornene cooperative catalysis. J. Am. Chem. Soc. 2020, 142, 6, 2715.

(10) a) S.-Q. Chen, Z.-S. Liu, T. Yang, Y. Hua, Z.-Y. Zhou, H.-G. Cheng, Q.-H. Zhou, Angew. Chem. Int. Ed. 2018, 57, 7161; b) G.-F. Shi, C.-D. Shao, X.-T. Ma, Y.-C. Gu, Y.-H. Zhang, ACS Catal. 2018, 8, 3775; c) R.-H. Li, F.-P. Liu, G.-B. Dong, Chem 2019, 5, 929.

(11) a) L. S. Hegedus, L. Wade, Preparation of carboxylic acids, acid halides and anhydrides. In compendium of organic synthetic methods, Vol. 3, John Wiley \& Sons, Hoboken, 1977; b) K. P. C. Vollhardt, N. E. Schore, Organische Chemie, 3rd ed., Wiley-VCH: Weinheim, 2000, pp. 893-952; c) I. I. Harrison, S. Harrison, Compendium of Organic Synthetic Methods., John Wiley \& Sons, Inc, Hoboken, NJ, 1971, pp. 16-74; d) K. Huang, C.-L. Sun, Z.-J. Shi, Chem. Soc. Rev. 2011, 40, 2435.

(12) A. G. Myers, D. Tanaka, M. R. Mannion, J. Am. Chem. Soc. 2002, 124, 11250.

(13) L. J. Gooßen, G. Deng, L. M. Levy, Science 2006, 313, 662.

(14) a) L. J. Gooßen, N. Rodríguez, K. Gooßen, Angew. Chem., Int. Ed. 2008, 47, 3100; b) N. Rodríguez, L. J. Gooßen, Chem. Soc. Rev. 2011, 40, 5030; c) Y. Wei, P. Hu, M. Zhang, W.-P. Su, Chem. Rev. 2017, 117, 8864.

(15) a) K. M. Engle, T.-S. Mei, M. Wasa, J.-Q. Yu, Acc. Chem. Res. 2012, 45, 788; b) M. P. Drapeau, L. J. Gooßen, Chem. Eur. J. 2016, 22, 18654; c) G.-F. Shi, Y.-H. Zhang, Adv. Synth. Catal. 2014, 356, 1419; d) J. Das, D. K. Mal, S. M. Maji, D. Maiti, ACS Catal. 2021, 11, 4205.

(16) a) M. Font, J. M. Quibell, G. J. P. Perry, I. Larrosa, Chem. Commun. 2017, 53, 5584; b) J. Cornella, M. Righi, I. Larrosa, Angew. Chem., Int. Ed. 2011, 50, 9429; c) A. Biafora, T. Krause, D. Hackenberger, F. Belitz, L. J. Gooßen, Angew. Chem. Int. Ed. 2016, 55, 14752; d) X. Just-Baringo, Y. Shin, A. Panigrahi, M. Zarattini, V. Nagyte, L. Zhao, K. Kostarelos, C. Casiraghi, I. Larrosa, Chem. Sci. 2020, 11, 2472. 
(17) a) J. He, D. Qiu, Y. Li, Acc. Chem. Res. 2020, 53, 508; b) E. K. $\quad$ Davison, J. Sperry, J. Nat. Prod. 2017, 80, 3060.

(18) E. Koch, A. Studer, Angew. Chem. Int. Ed. 2013, 52, 4933.

(19) E. J. Corey, K. C. Nicolaou, J. Am. Chem. Soc. 1974, 96, 5614.

(20) a) V. Hirschbeck, P. H. Gehrtz, I. Fleischer, Chem. Eur. J. 2018, 24, 7092; b) H. Prokopcová, C. O. Kappe, Angew. Chem. Int. Ed. 2009, 48, 2276; c) H.-G. Cheng, H. Chen, Y. Liu, Q.-H. Zhou, Asian J. Org. Chem. 2018, 7, 490.

(21) a) H. Lu, T.-Y. Yu, P.-F. Xu, H. Wei, Chem. Rev. 2021, 121, 365; b) H. Ochiai, Y. Uetake, T. Niwa, T. Hosoya, Angew. Chem. Int. Ed. 2017, 56, 2482.

(22) L. S. Liebeskind, J. Srogl, J. Am. Chem. Soc. 2000, 122, 11260.

(23) a) R. Uma, C. Crévisy, R. Grée, Chem. Rev. 2003, 103, 27; b) A. Vasseur, J. Bruffaerts, I. Marek, Nat. Chem. 2016, 8, 209; c) E. W. Werner, T.-S. Mei, A. J. Burckle, M. S. Sigman, Science. 2012, 338, 1455.

(24) a) K. Osakada, T. Yamamoto, A. Yamamoto, Tetrahedron Lett. 1987, 28, 6321; b) N. Ichiishi, C. A. Malapit, Ł. Woźniak, M. S. Sanford, Org. Lett. 2018, 20, 44; c) K. Ishitobi, K. Muto, J. Yamaguchi, ACS Catal. 2019, 9, 11685.

(25) a) C.-L. Zhu, Y.-F. Zhang, J. Kan, H.-Q. Zhao, W.-P. Su, Org. Lett. 2015, 17, 3418; b) E. Weis, M. J. Johansson, B. Martín-Matute, Chem. Eur. J. 2020, 26, 10185; c) C.-Q. Ye, H. Zhu, Z.-Y. Chen, J. Org. Chem. 2014, 79, 8900. 